\title{
Matrix isolation FTIR and theoretical study of $\alpha$-pyrone photochemistry $\dagger$
}

\author{
S. Breda, ${ }^{a b}$ I. Reva, ${ }^{a}$ L. Lapinski ${ }^{a b}$ and R. Fausto ${ }^{* a}$ \\ a Department of Chemistry, University of Coimbra, Coimbra P-3004-535, Portugal. \\ E-mail: rfausto@ci.uc.pt \\ ${ }^{\boldsymbol{b}}$ Institute of Physics, Polish Academy of Sciences, Warsaw PL-02-668, Poland
}

Received 12th August 2003, Accepted 15th December 2003

First published as an Advance Article on the web 27th January 2004

\begin{abstract}
A combined matrix isolation FTIR and molecular orbital study on the photochemistry of alpha-pyrone (AP) was undertaken. The most efficient of the observed photoprocesses was the Norrish type I, ring opening reaction leading to conjugated ketene. Upon irradiation of matrix isolated AP with UV $(\lambda>285 \mathrm{~nm})$ light, rapid formation of $\mathrm{Z}$ isomers of the aldehyde-ketene was observed. After a few minutes of irradiation the IR bands assigned to these photoproducts stopped growing. Further irradiation generated, by excited state internal rotations around the central $\mathrm{C}=\mathrm{C}$ bond in the $\mathrm{Z}$ forms, new aldehyde-ketene isomers, which were assigned to the $\mathrm{E}$ forms of the conjugated ketene. These forms were identified in the present work for the first time. Upon subsequent UV $(\lambda>337 \mathrm{~nm})$ irradiation, the $\mathrm{Z}$ aldehyde-ketene isomers reverted back to the closed-ring, initial form of AP, while the E forms did not react further. The ring opening reaction occurring upon UV $(\lambda>285 \mathrm{~nm})$ irradiation was accompanied by very slow valence isomerization of AP to the Dewar form (2-oxa-3-oxobicyclo[2.2.0]hex-5-ene; OOBH). Observation of cyclobutadiene, produced by shorter wavelength UV irradiation $(\lambda>235 \mathrm{~nm})$ of $\mathrm{OOBH}$, was also achieved in the present study. The structure of the cage confined complex of cyclobutadiene with $\mathrm{CO}_{2}$ was theoretically investigated. The possibility of formation of 4-formyl-2-cyclobutene-1-one, by photochemical ring closure of aldehyde-ketene isomers with the central $\mathrm{C}=\mathrm{C}$ bond and the ketene group in $s-c i s$ position with respect to each other is also discussed.
\end{abstract}

\section{Introduction}

The pyrone moiety is the fundamental structural nucleus of several naturally occurring coumarins, psoralens and chromones, which have been found to be potent photosensitizers. ${ }^{1,2}$ Pyrones are also very useful reagents in organic synthesis, as in the Diels Alder reaction, and shown to exhibit interesting photochemical properties.

First reports on the photochemistry of $\alpha$-pyrones come from the early work of de $\mathrm{Mayo}^{4}$ who observed an open-ring ester photoproduct generated from 4,6-dimethyl- $\alpha$-pyrone dissolved in methanol. A conjugated aldehyde-ketene was presumed to be the primary product of the photoreaction, although this intermediate species was not directly observed. Later on, Pirkle and McKendry ${ }^{5}$ photolyzed $\alpha$-pyrone (1) in a THF- $\mathrm{CH}_{2} \mathrm{Cl}_{2}$ glass, at $77 \mathrm{~K}$, and observed the appearance of a new IR band

+ Electronic supplementary information (ESI) available: Tables S1, $\mathrm{S} 2, \mathrm{~S} 3, \mathrm{~S} 12$ and S14 provide internal coordinates used in the normal modes analysis for $\boldsymbol{\alpha}$-pyrone, 2-oxa-3-oxobicyclo[2.2.0]hex-5-ene, open-ring aldehyde-ketene isomers, cyclobutadiene and 4-formyl-2cyclobutene-1-one. Experimental infrared spectra of $\boldsymbol{\alpha}$-pyrone isolated in Xe matrix are compared with the theoretical spectra in Fig. S1. Table S4 provides the assignment of infrared observed bands and the calculated vibrational frequencies, intensities and potential energy distribution for $\boldsymbol{\alpha}$-pyrone monomer. Calculated vibrational frequencies, intensities and potential energy distributions for all open-ring aldehyde-ketene conformers and for 4-formyl-2-cyclobutene-1-one monomer (forms A and B) are listed in Tables S5-S11 and Table $\mathrm{S} 15$, respectively. Table $\mathrm{S} 13$ provides the assignment of infrared observed bands and the calculated vibrational frequencies, intensities and potential energy distribution for cyclobutadiene monomer. Fig. $\mathrm{S} 2$ presents differential spectra showing the progress of the irradiation experiments. The optimized structure for the $\boldsymbol{\alpha}$-pyrone analogue of benzvalene is shown in Fig. S3. Fig. S4 illustrates the observed photochemistry of $\boldsymbol{\alpha}$-pyrone in an argon matrix. See http://www.rsc.org/ suppdata/cp/b3/b309660b/ at approximately $2140 \mathrm{~cm}^{-1}$, which was assigned to the Z-aldehyde-ketene (2).

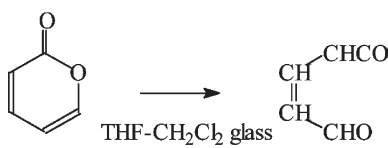

(1)

(2)

On the other hand, irradiation of a solution of $\alpha$-pyrone in ether at -10 to $-20^{\circ} \mathrm{C},{ }^{6}$ or lodged in cavity of hemicarceplex ${ }^{7}$ resulted in isomerization of the compound to its Dewar valence isomer (3), 2-oxa-3-oxobicyclo[2.2.0]hex-5-ene $(\mathrm{OOBH})$.

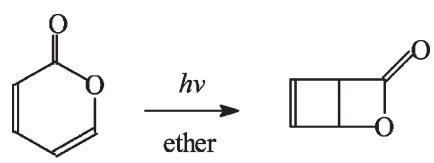

(3)

Later, Arnold et. al. ${ }^{8}$ have shown, using laser flash photolysis technique, that both conjugated ketene and OOBH are primary products of photochemical reaction of $\alpha$-pyrone in solutions.

The photochemistry of $\alpha$-pyrone was also studied using the matrix isolation technique..$^{9-11}$ In these studies, the open ring aldehyde-ketene was observed as the main product, being rapidly produced upon UV irradiation $(\lambda=313 \mathrm{~nm})$ of the matrix. The IR bands assigned to the aldehyde-ketene were interpreted on the basis of coexistence in the matrix of four isomers of the molecule, all exhibiting the $Z$ orientation at the double $\mathrm{C}=\mathrm{C}$ bond. The second photoproduct, $\mathrm{OOBH}$, was found to be generated very slowly under these experimental 
conditions. Indeed, conversion of a significant amount of the initial $\alpha$-pyrone into its Dewar valence isomer occurred only after prolonged irradiation of the matrix.

Upon UV irradiation through quartz, the matrix-isolated $\mathrm{OOBH}$ was found to decompose, with evolution of carbon dioxide and creation of antiaromatic cyclobutadiene. ${ }^{9,12}$ In the low temperature solid matrices, $\mathrm{CO}_{2}$ and cyclobutadiene are cage confined and found to form a complex. ${ }^{13,14}$

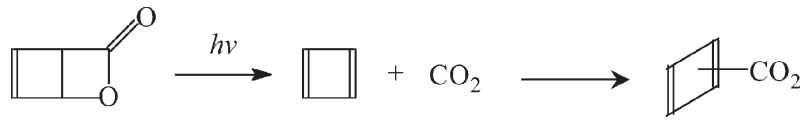

Recently, we have undertaken a combined matrix isolation and molecular orbital study of the vibrational spectra and photochemistry of 4,6-dimethyl- $\alpha$-pyrone. ${ }^{15}$ In agreement with the above mentioned studies, both types of photoreactions, ring opening leading to conjugate ketene and valence isomerization to the corresponding Dewar form (1,5dimethyl-2-oxa-3-oxobicyclo[2.2.0]hex-5-ene; DOOBH), were observed. Interestingly, in 4,6-dimethyl- $\alpha$-pyrone the latter reaction was found to be the most efficient photochemical process. The identification of the dominant photoproduct as DOOBH was unequivocal and the mid-IR spectrum of this species was fully assigned and interpreted. In addition, 1,3dimethyl-cyclobutadiene (DMCB), resulting from subsequent UV irradiation $(\lambda>235 \mathrm{~nm})$ of $\mathrm{DOOBH}$, was observed for the first time. Similarly to the cyclobutadiene produced by photolysis of matrix isolated $\mathrm{OOBH},{ }^{13,14}$ the antiaromatic DMCB was found to form a complex with $\mathrm{CO}_{2}$, confined in the same argon matrix cavity. The structure of the DMCB$\mathrm{CO}_{2}$ complex and its IR spectrum were analyzed based on the theoretical calculations.

In the present work, we report a matrix isolation study of the photochemistry of $\alpha$-pyrone (AP) and compare the results now obtained with those previously reported for 4,6-dimethyl$\alpha$-pyrone. ${ }^{15}$ The experimental studies are supported by extensive theoretical calculations. For $\alpha$-pyrone itself, both ring opening reaction leading to conjugated ketene photoproducts and valence isomerization to $\mathrm{OOBH}$ were observed, with the first type photochemistry dominating. Photoproduction of the $\mathrm{Z}$ as well as $\mathrm{E}$ forms of the conjugated ketene is spectroscopically proven for the first time. The possibility of subsequent isomerization of the conjugated ketene forms, with the central $\mathrm{C}=\mathrm{C}$ bond and the ketene group oriented $s-c i s$ to each other, into 4-formyl-2-cyclobutene-1-one is also discussed.

\section{Experimental}

AP was obtained from Aldrich (purity 98\%). A sample of the compound was placed in a glass tube protected against light and connected to the chamber of the cryostat with a needle valve. Before cooling down the cryostat, the compound was degassed by the standard freeze-pump-thaw procedure and, subsequently, the vapors over the compound in the tube were evacuated several times at room temperature. This approach enabled removal of possible volatile impurities, allowing an additional purification of the compound, immediately before experiment. In order to deposit a matrix, the vapor of AP was introduced into the cryostat chamber through the needle valve together with large excess of the host matrix gas (argon N60; krypton N48; xenon N45-all from Air Liquide) coming from a separate line. A cold CsI window mounted on the tip of an APD Cryogenics DE-202A closed-cycle helium refrigerator was used as the optical substrate. Care was taken to keep the guest-to-host ratio in matrices low enough to avoid association.

The matrices were irradiated through the outer $\mathrm{KBr}$ window of the cryostat, with filtered or unfiltered light from a $150 \mathrm{~W}$ xenon arc lamp (Osram XBO $150 \mathrm{~W} / \mathrm{CR}$ OFR).
The infrared spectra were recorded with $0.5 \mathrm{~cm}^{-1}$ resolution using a Mattson (60AR) Infinity Series FTIR spectrometer equipped with a $\mathrm{KBr}$ beamsplitter and a DTGS detector.

\section{Computational details}

The equilibrium geometries for all studied species were fully optimized at the DFT level of theory with the standard 6$311++\mathrm{G}(\mathrm{d}, \mathrm{p})$ basis set. The DFT calculations were carried out with the three-parameter density functional abbreviated as B3LYP, which includes Becke's gradient exchange correction, ${ }^{16}$ the Lee, Yang, Parr correlation functional ${ }^{17}$ and the Vosko, Wilk and Nusair ${ }^{18}$ correlation functional. No restriction of symmetry was imposed on the initial structures. The optimized geometry for AP and open-ring aldehyde-ketene isomers converged to structures with a planar heavy-atom backbone ( $C_{\mathrm{S}}$ symmetry).

Unless specified explicitly, the nature of the obtained stationary points on the potential energy surfaces of the respective systems was checked through the analysis of the corresponding Hessian matrix. A set of internal coordinates was defined and the Cartesian force constants were transformed to the internal coordinates space, allowing ordinary normal-coordinate analysis to be performed as described by Schachtschneider. ${ }^{19}$ The calculated harmonic frequencies (scaled as in ref. 15) were also used to assist the analysis of the experimental spectra and to account for the zero-point vibrational energy (ZPVE) corrections. Internal coordinate sets defined for AP, its Dewar isomer $(\mathrm{OOBH})$ and the openring ketene are given in Tables S1, S2 and S3 of the ESI. $\dagger$ Atom numbering schemes for the studied isomers of AP and for cyclobutadiene are provided in Fig. 1.

All calculations in this work were done using the Gaussian 98 program. ${ }^{20}$

\section{Results and discussion}

\section{Ring-opening photoreaction leading to the aldehyde-ketene, $\mathrm{CH}(=\mathrm{O}) \mathrm{CH}=\mathrm{CHCH}=\mathrm{C}=\mathrm{O}$}

The infrared spectrum of AP isolated in a Xe matrix is presented in Fig. S1 (in the ESI). The bands observed in this spectrum have their counterparts in the previously reported ${ }^{21}$ spectrum of AP isolated in an Ar matrix. Band assignments are shown in Table S4 of the ESI. $\dagger$

Upon UV irradiation, with a cut-off filter transmitting light with $\lambda>285 \mathrm{~nm}$, the intensities of the IR bands of AP decreased, whereas new sets of bands emerged. Observation of a group of bands in the $2140-2100 \mathrm{~cm}^{-1}$ spectral region (Fig. 2) indicated the generation of the conjugated ketene resulting from a $\alpha$-cleavage, Norrish type I photoreaction. These bands correspond to the characteristic ketene group antisymmetric stretching vibration, which is well known to give rise to a very intense infrared absorption. ${ }^{9-11,15}$
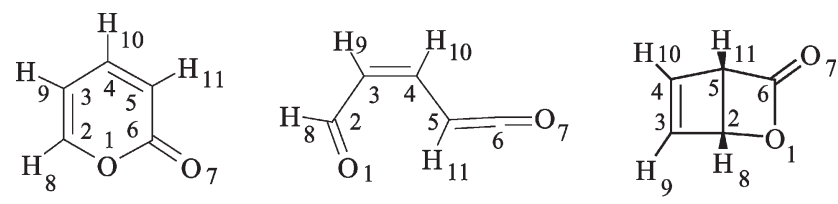<smiles>O=CC1C=CC=CC1C=O</smiles><smiles>C1=CC=C1</smiles>

Fig. 1 Atom numbering of $\alpha$-pyrone, ketene forms, Dewar isomer $(\mathrm{OOBH})$, cyclobutadiene (CB) and 4-formyl-2-cyclobutene-1-one (FCB). 

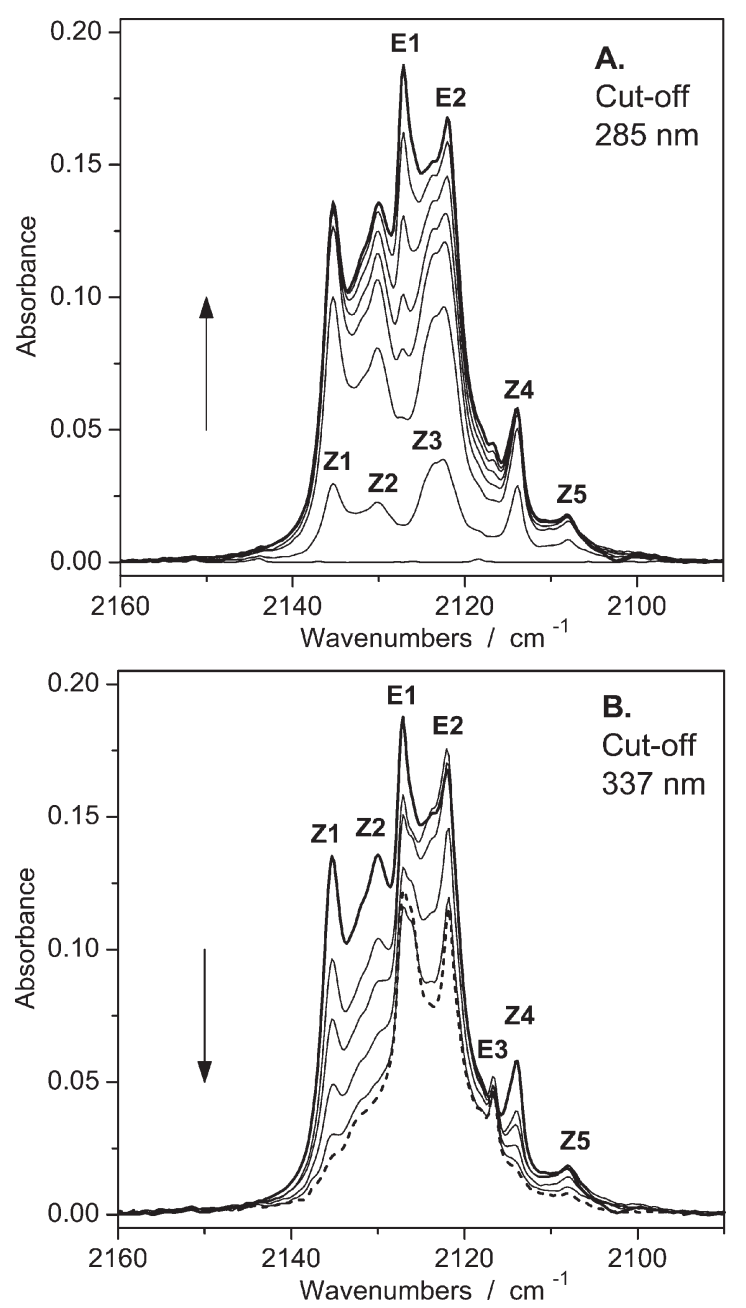

Fig. 2 Ketene antisymmetric stretching infrared spectral region. E and $\mathrm{Z}$ indicate bands assigned to $\mathrm{E}$ and $\mathrm{Z}$ ketene isomers, respectively (see text): (A) Progress of UV irradiation of $\alpha$-pyrone isolated in $\mathrm{Xe}$ matrix $(T=25 \mathrm{~K})$ using a Xenon arc lamp with a cut-off filter $\lambda>285 \mathrm{~nm}$. The traces correspond to recorded spectra after $0,1,6$, $11,17,32,42$ and $62 \mathrm{~min}$ of irradiation. The arrow indicates general direction of changes. (B) Progress of subsequent UV irradiation of $\alpha$-pyrone isolated in Xe matrix using a Xenon arc lamp with a cutoff filter $\lambda>337 \mathrm{~nm}$. Spectra recorded after 5, 10, 20, 30 and $55 \mathrm{~min}$ of irradiation. The arrow indicates general direction of changes.

In frame A of Fig. 2, the bottom spectrum, without any absorption bands, corresponds to AP in a xenon matrix immediately after deposition of the sample ( 0 minutes of irradiation). The other spectra shown in this frame, going from the bottom to the top of the figure, are registered after 1, 6, 11, $17,32,42$ and $62 \mathrm{~min}$ of UV irradiation $(\lambda>285 \mathrm{~nm})$. At the first stages of the UV-induced process, the new IR bands at $2135,2130,2124,2114$ and $2108 \mathrm{~cm}^{-1}$ were rapidly growing, whereas the bands of AP decreased in intensity. The growth of the 2135,2114 and $2108 \mathrm{~cm}^{-1}$ absorptions stopped after several minutes of irradiation. This result indicates that besides the photoreaction producing the isomers of aldehyde-ketene responsible for these absorptions, another photoprocess consuming these species must occur. The apparent increase in the peak intensity of the bands at 2130 and $2124 \mathrm{~cm}^{-1}$, after those at 2135, 2114 and $2108 \mathrm{~cm}^{-1}$ attained saturation, may be attributed to the partial overlap with the bands at 2127 and $2122 \mathrm{~cm}^{-1}$, which grow during the later stages of irradiation. Indeed, the two sharp bands at 2127 and $2122 \mathrm{~cm}^{-1}$ continue to grow at all the stages of irradiation (see Fig. S2 of the ESI $\dagger$ ). These features, which start to be discernible and increase visibly faster only after the population of the initially formed photoproduct was not growing any more, must be due to a different photoproduct. These observations suggest that this species forms at the expense of the initial photoproduct. Thus, the five bands (at 2135, 2130, 2124, 2114 and 2108 $\mathrm{cm}^{-1}$ ) can be assigned to the initially created photoproduct, whereas those at 2127 and $2122 \mathrm{~cm}^{-1}$ are spectral indications of another photoproduced species. During the total period of irradiation with the $285 \mathrm{~nm}$ cut-off filter $(62 \mathrm{~min})$, the amount of AP consumed was $c a .22 \%$, as estimated from the decrease in the peak intensity of the AP carbonyl stretching band at $1757 \mathrm{~cm}^{-1}$. In other words, $78 \%$ of the initially deposited AP were still present in the matrix.

In frame B of Fig. 2, the initial state is the last spectrum of frame A (recorded after $62 \mathrm{~min}$ of UV $(\lambda>285 \mathrm{~nm})$ irradiation; drawn with a thicker line). All subsequent irradiations were done with the $337 \mathrm{~nm}$ cut-off filter, the spectra being registered after $5,10,20,30$ and 55 min of irradiation. Irradiation with the longer wavelength $(\lambda>337 \mathrm{~nm})$ light led to photoreaction in reverse direction, having as a result partial recovery of AP. After $55 \mathrm{~min}$ of $(\lambda>337 \mathrm{~nm})$ irradiation, the amount of AP became equal to $c a$. $91 \%$ of the initial population of the compound (in the non-irradiated matrix), i.e., more than half of the AP consumed by irradiation at $\lambda>285 \mathrm{~nm}$ converted back to the original compound (this estimation was made using the relative intensities of the carbonyl stretching region in the relevant spectra). Five bands ascribed to the initial photoproduct resulting from irradiation of AP using the $285 \mathrm{~nm}$ cut-off filter reduced their intensity upon irradiation with the $337 \mathrm{~nm}$ cut-off filter. After $55 \mathrm{~min}$ of irradiation, these bands disappeared almost completely. On the other hand, the 2127 and $2122 \mathrm{~cm}^{-1}$ absorptions remained unchanged during the irradiation with the $337 \mathrm{~nm}$ filter (the observed simplification of the spectra in this region revealed a new small band at $2117 \mathrm{~cm}^{-1}$ that must be assigned to the same species responsible for those two bands). Hence, the UV $(\lambda>337 \mathrm{~nm})$ irradiation did not induce any photochemical processes consuming the species giving rise to the bands at 2127 and $2122 \mathrm{~cm}^{-1}$.

The identification of the different photoproducts manifesting themselves by the bands appearing at $2140-2100 \mathrm{~cm}^{-1}$ cannot be done using only this spectral region. Indeed, the conjugated ketene can exist in several possible stable isomeric forms (Fig. 3), but in the IR spectra of all of them a strong band due to antisymmetric stretching vibration of the ketene group should appear at nearly the same frequency. The relevant calculated vibrational data for all possible ketene isomeric forms are provided in Tables S5-S11 of the ESI). $\dagger$

In order to shed light on the structures of the different observed photoproducts, besides the $2140-2100 \mathrm{~cm}^{-1}$ region

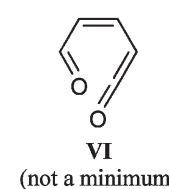

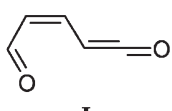

I

(not a minimum) $\Delta \mathrm{E}=2.3 \mathrm{~kJ} \mathrm{~mol}^{-1}$ $\mu=2.58 \mathrm{D}$

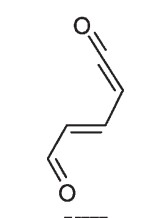

VIII

$\Delta \mathrm{E}=12.7 \mathrm{~kJ} \mathrm{~mol}^{-1}$

$\mu=3.34 \mathrm{D}$

III

$\mu=3.96 \mathrm{D}$

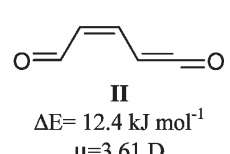

$\mu=3.61 \mathrm{D}$
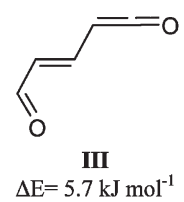
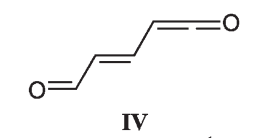

$\Delta \mathrm{E}=0.0 \mathrm{~kJ} \mathrm{~mol}^{-1}$

$\mu=4.04 \mathrm{D}$
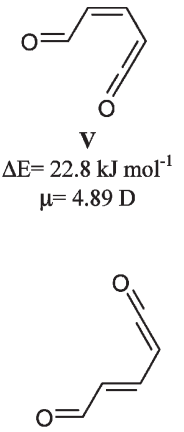

VI

$\Delta \mathrm{E}=6.7 \mathrm{~kJ} \mathrm{~mol}^{-1}$ $\mu=5.04 \mathrm{D}$
Fig. 3 Relative energies and dipole moments of conjugated aldehyde-ketene conformers theoretically calculated at the B3LYP $6-311++\mathrm{G}(\mathrm{d}, \mathrm{p})$ level with the zero point vibrational energy included. The energy of the most stable form IV $\left(-343.358983 E_{\mathrm{h}}\right)$ was taken as a reference. This form was calculated to be $72.7 \mathrm{~kJ} \mathrm{~mol}^{-1}$ higher in energy than $\alpha$-pyrone. 
other spectral ranges must be analyzed. The most intense bands in the infrared spectra of the various conformers of the conjugated aldehyde-ketene are those due to: $-\mathrm{C}=\mathrm{C}=\mathrm{O}$ antisymmetric stretching (described above), aldehyde $\mathrm{C}=\mathrm{O}$ and $\mathrm{C}=\mathrm{C}$ stretching vibrations. The IR bands corresponding to the last two vibrations are expected in the 1800-1500 $\mathrm{cm}^{-1}$ region (presented in Fig. 4).

Similarly to the bands observed in the $2140-2100 \mathrm{~cm}^{-1}$ spectral range, two types of behavior upon UV $(\lambda>285 \mathrm{~nm}$ and $\lambda>337 \mathrm{~nm}$ ) irradiation were also observed for the photoproducts bands appearing in the $1800-1500 \mathrm{~cm}^{-1}$ region. Three bands showing one type of the characteristic dependency on irradiation time and the wavelength of light were observed in this region. For the other type, also three bands were found. Because each conformer of aldehyde-ketene is expected to give rise to two absorptions in the considered range, the results shown in Fig. 4 indicate that there must be two (or more) different conformers corresponding to the initial as well as secondary photoproducts. The observed bands of aldehydeketene conformers can be best interpreted on the basis of theoretical calculations (Fig. 4A and B), when one assumes that the initial photoproduct is a mixture of two conformers (I and II) with $Z$ orientation at the central $\mathrm{C}=\mathrm{C}$ bond, and that the second photoproduct corresponds to the $\mathrm{E}$ isomer, with all probability adopting conformations III and IV. These conclusions are reinforced by the analysis of other spectral
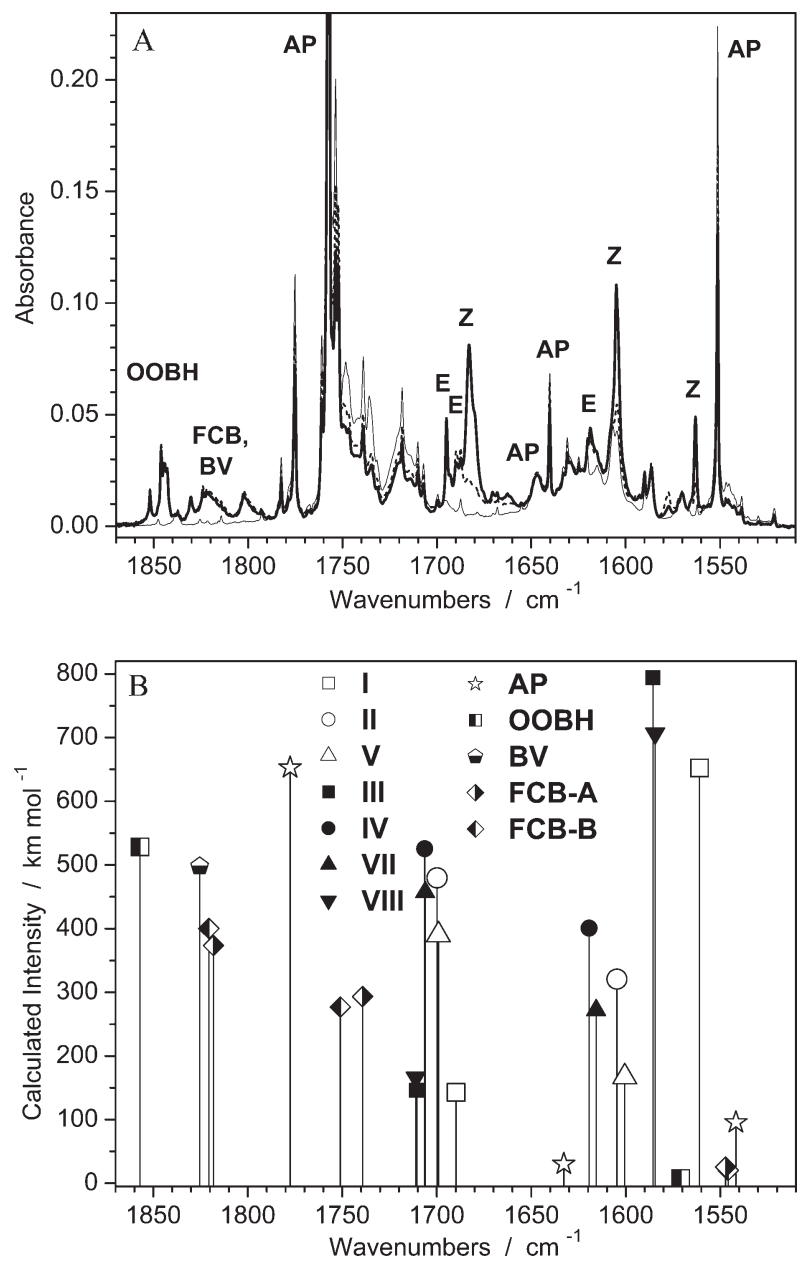

Fig. 4 (A) Thin sold line spectrum recorded after deposition of the Xe matrix; thick solid line after 62 min of UV irradiation with a cutoff filter $\lambda>285 \mathrm{~nm}$; dashed line recorded after $55 \mathrm{~min}$ of UV irradiation with a cut-off filter $\lambda>337 \mathrm{~nm}$. (B) Calculated (B3LYP/ $6-311++\mathrm{G}(\mathrm{d}, \mathrm{p}))$ spectra of $\alpha$-pyrone isomers: all ketene forms (see Fig. 3), OOBH, FCB (see Fig. 1) and the benzvalene-like isomer (BV) (see Fig. S2 in the ESI)†) in the spectral region between 1870 $1500 \mathrm{~cm}^{-1}$. Theoretical frequencies were scaled with the factor 0.978 . regions, e.g., the $1300-1100 \mathrm{~cm}^{-1}$ range (presented in Fig. 5). A particular indication of the correctness of the assignment of the second type of photoproducts to $\mathrm{E}$ isomers of the aldehyde-ketene is the appearance of a relatively strong experimental band at $1141 \mathrm{~cm}^{-1}$. This band continues to grow and increases significantly upon prolonged UV $(\lambda>285 \mathrm{~nm})$ irradiation, while the growth of the bands due to $\mathrm{Z}$ isomers (e.g. those at 1236 and $1224 \mathrm{~cm}^{-1}$ ) is already saturated (traces $b$ and $\mathrm{c}$ in Fig. 5A). Moreover, the intensity of the band at $1141 \mathrm{~cm}^{-1}$ does not change much upon UV $(\lambda>337 \mathrm{~nm})$ irradiation, while those corresponding to the absorptions at 1236 and $1224 \mathrm{~cm}^{-1}$ diminish significantly (traces $\mathrm{c}$ and $\mathrm{d}$ in Fig. $5 \mathrm{~A})$. Hence, the band at $1141 \mathrm{~cm}^{-1}$ exhibits a behaviour that was interpreted above as characteristic of the $\mathrm{E}$ isomers. Theoretical calculations predict two comparatively strong bands near these frequencies (at 1144 and $1121 \mathrm{~cm}^{-1}$ ) for the E type conformer IV. The lower frequency band coincides in the experimental spectrum with a band of AP. It should be stressed, that at similar frequencies no bands with significant intensities are theoretically predicted for any of the $\mathrm{Z}$ isomers of conjugated ketene. The proposed assignments of the experimental bands due to aldehyde-ketene to the theoretically predicted spectra of conformers I, II, III and IV are summarized in Table 1.

Different isomers of the conjugated ketene created in the $\alpha$-cleavage photoreaction of AP were previously considered. ${ }^{10,11,22}$ However, these considerations were restricted to
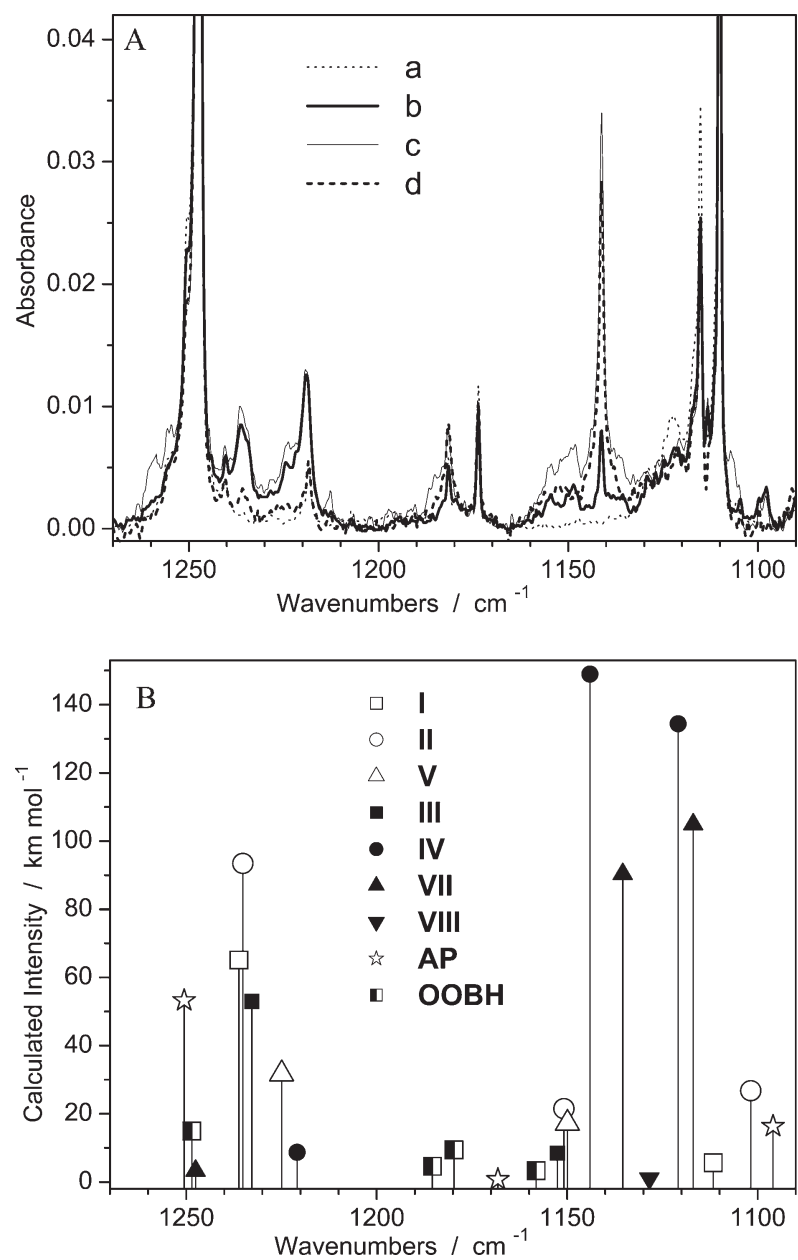

Fig. 5 (A) a: spectrum of $\alpha$-pyrone recorded after deposition of the $\mathrm{Xe}$ matrix; b: after $11 \mathrm{~min}$ of UV irradiation with a cut-off filter $\lambda>285$ $\mathrm{nm}$; c: after $62 \mathrm{~min}$ of UV irradiation with a cut-off filter $\lambda>285 \mathrm{~nm}$; $\mathrm{d}$ : after $55 \mathrm{~min}$ of UV irradiation with a cut-off filter $\lambda>337 \mathrm{~nm}$. (B) Calculated (B3LYP/6-311++G(d, p)) spectra of $\alpha$-pyrone isomers: AP, OOBH, I-VIII mean the same as in Fig. 3. Theoretical frequencies were scaled with the factor 0.978 . 
Table 1 Observed bands ascribed to the aldehyde-ketene, calculated vibrational frequencies, intensities and potential energy distributions (PED) of aldehyde-ketene isomers

\begin{tabular}{|c|c|c|c|c|c|c|}
\hline \multicolumn{2}{|c|}{ Observed (infrared, Xe matrix, $T=25 \mathrm{~K}$ ) } & \multirow[b]{2}{*}{$d$} & \multirow[b]{2}{*}{$e$} & \multicolumn{3}{|c|}{ Calculated $[\mathrm{DFT}(\mathrm{B} 3 \mathrm{LYP}) / 6-311++\mathrm{G}(\mathrm{d}, \mathrm{p})]^{a}$} \\
\hline$\nu^{b}$ & $I^{c}$ & & & $\nu^{f}$ & $I^{g}$ & $\operatorname{PED}^{h}(\%)$ \\
\hline 2135.3 & vs & $\mathrm{Z1}$ & & & & \\
\hline 2132.4 & vs & Z & & & & \\
\hline 2130.2 & vs & $\mathrm{Z2}$ & II & 2165.8 & 1357.2 & $\nu(\mathrm{C} 6=\mathrm{O} 7)(74.1)+\nu(\mathrm{C} 5=\mathrm{C} 6)(25.7)$ \\
\hline 2127.2 & vs & E1 & IV & 2165.2 & 1372.9 & $\nu(\mathrm{C} 6=\mathrm{O} 7)(74.2)+\nu(\mathrm{C} 5=\mathrm{C} 6)(25.5)$ \\
\hline 2123.6 & vs & $\mathrm{Z3}$ & I & 2160.3 & 1453.4 & $\nu(\mathrm{C} 6=\mathrm{O} 7)(74.7)+\nu(\mathrm{C} 5=\mathrm{C} 6)(25.0)$ \\
\hline 2122.0 & vs & E2 & III & 2164.8 & 1355.0 & $\nu(\mathrm{C} 6=\mathrm{O} 7)(74.6)+\nu(\mathrm{C} 5=\mathrm{C} 6)(25.0)$ \\
\hline 2116.6 & $\mathrm{~s}$ & E3 & & & & \\
\hline 2113.9 & $\mathrm{~s}$ & $\mathrm{Z4}$ & & & & \\
\hline 2108.0 & $\mathrm{~m}$ & $\mathrm{Z} 5$ & & & & \\
\hline 1694.9 & $\mathrm{~s}$ & $\mathrm{E}$ & III & 1710.7 & 145.9 & $\nu(\mathrm{O} 1=\mathrm{C} 2)(73.8)$ \\
\hline 1689.5 & $\mathrm{~m}$ & $\mathrm{E}$ & IV & 1706.3 & 525.5 & $\nu(\mathrm{O} 1=\mathrm{C} 2)(88.1)$ \\
\hline 1683.2 & $\mathrm{~s}$ & $\mathrm{Z}$ & II & 1699.8 & 479.6 & $\nu(\mathrm{O} 1=\mathrm{C} 2)(87.7)$ \\
\hline 1682.6 & $\mathrm{~s}$ & Z & I & 1689.8 & 143.1 & $\nu(\mathrm{O} 1=\mathrm{C} 2)(69.3)+\nu(\mathrm{C} 3=\mathrm{C} 4)(10.0)$ \\
\hline 1618.9 & $\mathrm{~m}$ & $\mathrm{E}$ & IV & 1619.3 & 400.6 & $\nu(\mathrm{C} 3=\mathrm{C} 4)(58.5)+\nu(\mathrm{C} 6=\mathrm{O} 7)(14.8)$ \\
\hline 1605.1 & $\mathrm{~s}$ & $\mathrm{Z}$ & II & 1604.7 & 320.6 & $\nu(\mathrm{C} 3=\mathrm{C} 4)(61.6)+\delta(\mathrm{C} 4-\mathrm{H} 10)^{\prime \prime}(11.1)$ \\
\hline 1563.1 & $\mathrm{~s}$ & $\mathrm{Z}$ & I & 1560.9 & 652.3 & $\begin{array}{l}\nu(\mathrm{C} 3=\mathrm{C} 4)(48.7)+\nu(\mathrm{O} 1=\mathrm{C} 2)(15.4) \\
\quad+\delta(\mathrm{C} 4-\mathrm{H} 10)^{\prime \prime}(10.9)\end{array}$ \\
\hline 1313.3 & $\mathrm{~m}$ & Z & II & 1315.6 & 14.4 & $\begin{array}{l}\delta(\mathrm{C} 5-\mathrm{H} 11)^{\prime \prime}(24.1)+\delta(\mathrm{C} 4-\mathrm{H} 10)^{\prime \prime}(24.1) \\
\quad+\nu(\mathrm{C} 5=\mathrm{C} 6)(21.0)\end{array}$ \\
\hline 1282.0 & $\mathrm{~m}$ & $\mathrm{E}$ & III & 1288.5 & 28.1 & $\begin{array}{l}\delta(\mathrm{C} 4-\mathrm{H} 10)^{\prime \prime}(40.3)+\delta(\mathrm{C} 3-\mathrm{H} 9)^{\prime \prime}(23.9) \\
\quad+\nu(\mathrm{C} 3=\mathrm{C} 4)(22.5)\end{array}$ \\
\hline 1236.0 & $\mathrm{~s}$ & $\mathrm{Z}$ & I & 1236.2 & 65.1 & $\begin{array}{l}\delta(\mathrm{C} 4-\mathrm{H} 10)^{\prime \prime}(40.1)+\delta(\mathrm{C} 3-\mathrm{H} 9)^{\prime \prime}(28.1) \\
\quad+\nu(\mathrm{C} 4-\mathrm{C} 5)(13.2)+\nu(\mathrm{C} 3=\mathrm{C} 4)(12.3)\end{array}$ \\
\hline 1233.0 & w & & & & & \\
\hline 1224.1 & $\mathrm{~s}$ & $\mathrm{Z}$ & II & 1235.1 & 93.4 & $\begin{array}{l}\delta(\mathrm{C} 3-\mathrm{H} 9)^{\prime \prime}(45.1)+\delta(\mathrm{C} 4-\mathrm{H} 10)^{\prime \prime}(25.8) \\
\quad+\nu(\mathrm{C} 4-\mathrm{C} 5)(12.8)\end{array}$ \\
\hline 1155.0 & w & Z & II & 1150.9 & 21.5 & $\begin{array}{l}\delta(\mathrm{C} 5-\mathrm{H} 11)^{\prime \prime}(21.4)+\nu(\mathrm{C} 2-\mathrm{C} 3)(20.2) \\
\quad+\nu(\mathrm{C} 4-\mathrm{C} 5)(17.5) \\
\quad+\delta(\mathrm{C} 3-\mathrm{H} 9)^{\prime \prime}(11.7)\end{array}$ \\
\hline 1148.0 & w & & & & & \\
\hline \multirow[t]{2}{*}{1141.4} & $\mathrm{~s}$ & $\mathrm{E}$ & IV & 1144.0 & 149.0 & $\begin{array}{l}\delta(\mathrm{C} 5-\mathrm{H} 11)^{\prime \prime}(33.1)+\nu(\mathrm{C} 4-\mathrm{C} 5)(27.9) \\
\quad+\delta(\mathrm{C} 3-\mathrm{H} 9)^{\prime \prime}(13.7)\end{array}$ \\
\hline & & & IV & 1120.8 & 134.4 & $\nu(\mathrm{C} 2-\mathrm{C} 3)(40.5)+\delta(\mathrm{C} 5-\mathrm{H} 11)^{\prime \prime}(29.0)$ \\
\hline 978.8 & $\mathrm{~m}$ & $\mathrm{Z}$ & II & 969.2 & 70.3 & $\nu(\mathrm{C} 4-\mathrm{C} 5)(25.4)+\nu(\mathrm{C} 2-\mathrm{C} 3)(23.3)$ \\
\hline 956.0 & w & $\mathrm{E}$ & IV & 963.1 & 43.7 & $\begin{array}{l}\gamma(\mathrm{C} 3-\mathrm{H} 9)(45.3)+\gamma(\mathrm{C} 4-\mathrm{H} 10)(43.9) \\
\quad+\gamma(\mathrm{C} 2-\mathrm{H} 8)(17.8)\end{array}$ \\
\hline \multicolumn{7}{|c|}{ 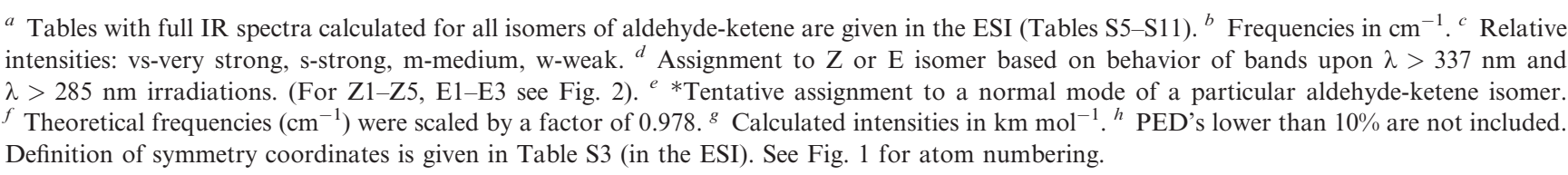 } \\
\hline
\end{tabular}

the $\mathrm{Z}$ isomers only. In the present work, theoretical geometry optimizations, electronic energy calculations and IR spectrum predictions were carried out for the whole set of eight possible forms of the open-ring ketene (see Fig. 3).

Conjugated ketenes are often graphically represented as form VI. ${ }^{10,11,22-24}$ The theoretical calculations carried out within the present work show that form VI does not correspond to a minimum on the potential energy hypersurface of the aldehyde-ketene. According to the calculations, ketene in form VI should barrierless close the ring, which would lead to the initial AP molecule. Hence, isomer VI should be excluded from the list of possible open-ring photoproduct structures.

Relative energies calculated for the whole set of aldehydeketene isomers are presented in Fig. 3. The most stable conformer (form IV) corresponds to a molecule with the $\mathrm{E}$ arrangement around the $\mathrm{C}=\mathrm{C}$ central double bond having its alternate double bonds $(\mathrm{C}=\mathrm{O}, \mathrm{C}=\mathrm{C}$ and $\mathrm{C}=\mathrm{CO})$ trans to each other. This spatial arrangement guarantees maximum delocalization of the $\pi$ electron system of the molecule and minimizes the steric interatomic repulsive interactions. Forms III and VII are also E isomers, which differ from IV by rotation of the aldehyde or ketene group, respectively. These conformers have energies higher by 5.7 and $6.7 \mathrm{~kJ} \mathrm{~mol}^{-1}$ with respect to the most stable form IV. The increases in energy can be associated with the reduction of importance of the $\pi$ electron system delocalization in the cis arrangement of the $\mathrm{O}=\mathrm{CH}-\mathrm{CH}=\mathrm{CH}$ or $\mathrm{CH}=\mathrm{CH}-\mathrm{C}=\mathrm{CO}$ groups. The remaining $\mathrm{E}$ form (VIII) has an excess energy relatively to form IV that is nearly the sum of the energy differences between forms III and VII and the conformational ground state: $12.7 \mathrm{~kJ} \mathrm{~mol}^{-1}$. In form VIII both aldehyde and ketene groups are rotated by $180^{\circ}$ with respect to the most stable form. Hence, for the $\mathrm{E}$ arrangement around the $\mathrm{C}=\mathrm{C}$ central bond the gain in energy due to the trans $\rightarrow$ cis conformational changes of the aldehyde and ketene groups seem to be additive and equal to $c a$. 6 and $7 \mathrm{~kJ} \mathrm{~mol}^{-1}$, respectively. In the case of the $\mathrm{Z}$ forms around the $\mathrm{C}=\mathrm{C}$ central bond the situation is a bit more complex, since steric repulsions become considerably more important. Form V exhibits a relatively important destabilizing steric interaction between the aldehyde hydrogen and the ketene group, corresponding to a high energy conformer that is $22.8 \mathrm{~kJ} \mathrm{~mol}^{-1}$ higher in energy 
than the most stable isomer. On the contrary, form I is only less stable than form IV by $2.3 \mathrm{~kJ} \mathrm{~mol}^{-1}$, since it exhibits a weak stabilizing intramolecular hydrogen bond-like interaction between the aldehyde oxygen and the hydrogen atom connected to the alkene carbon atom of the ketene group (see Fig. 3).

As mentioned above, the spectroscopic data presented here show that both Z (forms I and II) and E (IV and most probably III $\ddagger$ ) isomers are photoproduced upon UV irradiation of matrix isolated AP. The four isomers experimentally identified correspond to the two most stable E forms and to the two most stable $\mathrm{Z}$ forms. Indeed, it is likely that III is produced directly from I and IV from II by excited state internal rotation around the central carbon-carbon double bond, in a similar way to the previously observed photochemically induced $\mathrm{E} \rightarrow \mathrm{Z}$ isomerizations in simple matrix-isolated $\alpha, \beta$-unsaturated carboxylic compounds. ${ }^{25,26}$

Both experimental and theoretical arguments given above support the correctness of the statement that $\mathrm{E}$ isomers of the aldehyde-ketene (not considered in the previous works) are effectively generated upon prolonged UV irradiation of AP

\section{AP valence isomerization to 2-oxa-3-oxobicyclo[2.2.0]hex-5-ene (OOBH)}

In consonance with earlier observations, ${ }^{6,9-11}$ the ring opening and ring closure photoreactions observed in the present work were found to be accompanied by a slow irreversible production of the Dewar isomer of AP (2-oxa-3-oxobicyclo[2.2.0]hex-5-ene; OOBH). This is evidenced by the appearance of the very characteristic $\nu \mathrm{C}=\mathrm{O}$ band at $c a .1846 \mathrm{~cm}^{-1}$ (Fig. 4) as well as of other new bands from the spectrum of the Dewar form (e.g., the band $1181.6 \mathrm{~cm}^{-1}$, presented in Fig. 5). The observed spectrum of this species is well reproduced by the theoretical predictions (see the assignments provided in Table 2).

Comparing the photoreactions observed for AP with those of 4,6-dimethyl- $\alpha$-pyrone, ${ }^{15}$ it can be concluded that the Dewar isomer formation is much more effective in the case of the dimethyl derivative, while the $\alpha$-cleavage photoreaction, leading to the aldehyde-ketene, proceeds easier for unsubstituted $\alpha$-pyrone. Matrix isolation study of the ring opening and valence isomerization to the Dewar form, previously carried out for methylated and non-methylated 4(3H)-pyrimidinones, ${ }^{27}$ led to analogous conclusions, with the first process being more efficient for the unsubstituted molecule and the latter for the methylated compound.

Norrish type I, $\alpha$-cleavage processes are believed ${ }^{28,29}$ to originate from the excited states with $n \pi^{*}$ character, whereas formation of Dewar isomers should proceed starting from the excited $\pi \pi^{*}$ state. In $\alpha$-pyrones, which are six-membered ring compounds with the double bond of the carbonyl group linearly conjugated with two double bonds in the ring, the lowest excited singlet state has $n \pi^{*}$ character. ${ }^{3}$ Hence, the $n \pi^{*}$-type photochemistry should be favored for such compounds, especially when they are free of any substituents. Methyl substituents attached to the ring led to an effective extension of the $\pi$-electron system of a molecule, by hyperconjugation. As a consequence, the energy gap between the ground state and the $\pi \pi^{*}$ excited state should diminish and the gap between the ground and the $n \pi^{*}$ state should increase. ${ }^{3,30}$ This effect should promote the photoreactions like Dewar isomer formation with increasing number of methyl substituents, whereas the reactions typical for $n \pi^{*}$ photochemistry should be hindered for

$\ddagger$ The vibrational signatures of forms III and VII are quite similar, thus making the identification of III not so unequivocal than for the remaining forms (I, II and IV). However, the forthcoming discussion presents other considerations pointing to the assignment of the second E conformer to form III rather than to VII. methylated derivatives, as it was experimentally observed for $\alpha$-pyrone and 4,6-dimethyl- $\alpha$-pyrone. ${ }^{15}$

\section{Cyclobutadiene photoproduction from irradiated $(\lambda>235 \mathrm{~nm})$} OOBH

As was reported previously, ${ }^{9,14,31}$ and as follows from the experiments carried out in the present work, irradiation of the matrix-isolated $\mathrm{OOBH}$ with shorter wavelength UV light $(\lambda>235 \mathrm{~nm})$ leads to evolution of $\mathrm{CO}_{2}$ and to creation of antiaromatic cyclobutadiene. The bands at 1239 and 574 $\mathrm{cm}^{-1}(\mathrm{Xe})$, analogous to the previously reported bands at 1241 and $575 \mathrm{~cm}^{-1}(\mathrm{Ar})^{9}$ clearly revealed the production of this molecule. After photolysis, the photoproduced $\mathrm{CO}_{2}$ and cyclobutadiene must be confined in the same matrix cavity and they orm a complex. As previously found in the analogous case of 1,2-dimethylcyclobutadiene photoproduced from 1,5dimethyl-2-oxa-3-oxobicyclo[2.2.0] hex-5-ene (DOOBH), ${ }^{15}$ the DFT(B3LYP) $/ 6-311++\mathrm{G}(\mathrm{d}, \mathrm{p})$ calculations predict that the $\mathrm{CO}_{2}$-cyclobutadiene complex has a stacking (parallel) geometry. Fig. 6 represents two potential scans for the $\mathrm{CO}_{2}$-cyclobutadiene complex assuming two different orientations within the $\mathrm{C}_{2}$ symmetry framework: one with the axial orientation and the other with the parallel orientation to the cyclobutadiene plane. The first scan (axial) reveals a repulsive potential of interaction between $\mathrm{CO}_{2}$ and cyclobutadiene. On the other hand, the second one (parallel) shows a binding profile with an equilibrium minimum energy distance between the two molecules of $c a .3 .45 \AA$ and a stabilization energy of the complex equal to $3.45 \mathrm{~kJ} \mathrm{~mol}^{-1}$. The IR spectrum calculated for the stacked $\mathrm{CO}_{2}$-cyclobutadiene complex fits nicely the experimental spectrum of the photoproduct(s) generated upon irradiation of the matrix with $\mathrm{UV}(\lambda>235 \mathrm{~nm})$ light. Tables S12 and S13 of the ESI $\dagger$ summarize the results of normal coordinate analysis and the proposed band assignments for this species.

\section{Ring-closure ketene isomerization leading to 4-formyl-2-cyclobutene-1-one}

The energy barriers separating the different conformers of the photoproduced aldehyde-ketene (Fig. 3) in the ground electronic state were estimated theoretically. The results are presented in Table 3. These barriers are all high enough to prevent thermal isomerization reactions to take place in the $S_{0}$ potential energy surface for the low temperature matrix-isolated compound. Tunneling may also be neglected, since all possible isomerizations involve the movement of heavy atoms. Hence, all observed ketene forms must result from photochemical processes. As described in the previous sections of this paper, Z forms are directly obtained from AP, while E forms result from $\mathrm{Z}$ species by internal rotation around the central $\mathrm{C}=\mathrm{C}$ bond in the excited state.

In the excited state, the aldehyde-ketene shall adopt preferentially conformations where the $\mathrm{C}-\mathrm{C}=\mathrm{C}-\mathrm{C}$ dihedral angle is ca. $90^{\circ}$, as is usually the case for $\alpha, \beta$-unsaturated carbonyl compounds. ${ }^{25,32}$ Starting from such excited state geometry the system can adopt, during dissipation of energy excess, either $\mathrm{Z}$ or $\mathrm{E}$ orientation at the $\mathrm{C}=\mathrm{C}$ double bond. Because the barriers for rotations around single $\mathrm{C}-\mathrm{C}$ bonds are much lower than the electronic excitation energy, the rotations around such bonds should be possible for a molecule carrying large excess of energy gained by absorption of UV photon. Hence, in principle, all the possible isomers of conjugated aldehyde-ketene should be accessible on the photochemical way. However, no spectral signatures that can be reliably assigned to forms V, VII and VIII were observed in the experimental IR spectra of UV irradiated matrices. All these structures have the ketene group and the central $\mathrm{C}=\mathrm{C}$ bond in the $s$-cis geometry (see Fig. 3). 
Table 2 Observed and calculated vibrational frequencies ${ }^{a}$, intensities and potential energy distributions (PED) for 2-oxa-3-oxobicyclo[2.2.0]hex-5ene monomer (Dewar valence isomer of $\alpha$-pyrone)

\begin{tabular}{|c|c|c|c|c|}
\hline \multicolumn{2}{|c|}{ Observed (infrared, Xe matrix, $T=25 \mathrm{~K}$ ) } & \multicolumn{3}{|c|}{ Calculated [DFT(B3LYP)/6-311++G(d, p)] } \\
\hline$\nu^{a}$ & $I^{b}$ & $\nu^{a}$ & $I^{c}$ & $\mathrm{PED}^{d}(\%)$ \\
\hline & & 3120.9 & 7.3 & $\nu(\mathrm{C} 3-\mathrm{H} 9)(61.7)+\nu(\mathrm{C} 4-\mathrm{H} 10)(36.3)$ \\
\hline & & 3092.1 & 4.2 & $\nu(\mathrm{C} 4-\mathrm{H} 10)(62.6)+\nu(\mathrm{C} 3-\mathrm{H} 9)(36.7)$ \\
\hline & & 3054.1 & 14.1 & $\nu(\mathrm{C} 2-\mathrm{H} 8)(96.9)$ \\
\hline & & 3030.2 & 8.2 & $\nu(\mathrm{C} 5-\mathrm{H} 11)(97.4)$ \\
\hline 1846.1 & 618.5 & 1857.1 & 528.2 & $\nu(\mathrm{C} 6=\mathrm{O} 7)(88.8)$ \\
\hline \multicolumn{5}{|l|}{1844.5} \\
\hline 1577.4 & 48.6 & 1571.0 & 7.5 & $\nu(\mathrm{C} 3=\mathrm{C} 4)(86.5)$ \\
\hline \multirow[t]{3}{*}{1282.0} & 39.2 & 1275.6 & 37.4 & $\begin{array}{l}\delta(\mathrm{C} 3-\mathrm{H} 9)(27.8)+\delta(\mathrm{C} 4-\mathrm{H} 10)(24.0)+\gamma(\mathrm{C} 2-\mathrm{H} 8) \\
\quad+\nu(\mathrm{C} 2-\mathrm{C} 3)(16.8)\end{array}$ \\
\hline & & 1248.5 & 15.0 & $\gamma(\mathrm{C} 2-\mathrm{H} 8)(53.5)+\delta(\mathrm{C} 4-\mathrm{H} 10)(11.8)+\nu(\mathrm{C} 6-\mathrm{O} 1)$ \\
\hline & & 1185.4 & 4.6 & $\begin{array}{l}\gamma(\mathrm{C} 5-\mathrm{H} 11)(33.5)+\delta(\mathrm{C} 2-\mathrm{H} 8)(13.8)+\nu(\mathrm{C} 5-\mathrm{C} 2) \\
\quad+\delta(\mathrm{C} 3-\mathrm{H} 9)(13.7)\end{array}$ \\
\hline \multirow[t]{2}{*}{1181.0} & 10.2 & 1179.7 & 9.4 & $\gamma(\mathrm{C} 5-\mathrm{H} 11)(38.6)+\delta(\mathrm{C} 2-\mathrm{H} 8)(19.8)+\nu(\mathrm{C} 5-\mathrm{C} 2)(15.7)$ \\
\hline & & 1158.1 & 3.3 & $\begin{array}{l}\delta(\mathrm{C} 5-\mathrm{H} 11)(49.2)+\delta(\mathrm{C} 2-\mathrm{H} 8)(14.0)+\delta(\mathrm{C} 4-\mathrm{H} 10) \\
\quad+\nu(\mathrm{C} 5-\mathrm{C} 2)(11.1)\end{array}$ \\
\hline 1072.4 & 4.4 & 1059.0 & 7.5 & $\delta(\mathrm{C} 4-\mathrm{H} 10)(27.6)+\delta(\mathrm{C} 3-\mathrm{H} 9)(23.6)+\delta(\mathrm{C} 5-\mathrm{H} 11)$ \\
\hline 1069.3 & 20.9 & 1050.2 & 79.9 & $\begin{array}{l}\nu(\mathrm{C} 6-\mathrm{O} 1) \\
\quad+\nu(\mathrm{C} 5-\mathrm{C} 6)(12.1)+\gamma(\mathrm{C} 2-\mathrm{H} 8)(11.9)\end{array}$ \\
\hline \multirow[t]{2}{*}{1062.4} & 16.8 & & & \\
\hline & & 978.3 & 3.1 & $\nu(\mathrm{C} 4-\mathrm{C} 5)(24.8)+\nu(\mathrm{C} 2-\mathrm{C} 3)(24.2)+\delta(\mathrm{C} 3-\mathrm{H} 9)(10.3)$ \\
\hline \multirow[t]{2}{*}{970.9} & 13.7 & 964.6 & 8.2 & $\delta \operatorname{ring} 1(25.9)+\delta \operatorname{ring} 2(19.0)+\nu(\mathrm{C} 5-\mathrm{C} 6)(9.9)$ \\
\hline & & 945.0 & 1.3 & $\gamma(\mathrm{C} 4-\mathrm{H} 10)(43.5)+\gamma(\mathrm{C} 3-\mathrm{H} 9)$ \\
\hline 906.2 & 17.2 & 901.7 & 24.6 & $\begin{array}{l}\nu(\mathrm{C} 4-\mathrm{C} 5)(20.4)+\nu(\mathrm{C} 2-\mathrm{C} 3)(17.4)+\gamma(\mathrm{C} 4-\mathrm{H} 10) \\
\quad+\delta \operatorname{ring} 2(11.2)\end{array}$ \\
\hline 880.9 & 12.1 & 875.0 & 13.8 & $\begin{array}{l}\delta(\mathrm{C} 2-\mathrm{H} 8)(26.9)+\nu(\mathrm{C} 5-\mathrm{C} 2)(17.8)+\delta \text { ring } 2 \\
\quad+\delta(\mathrm{C} 5-\mathrm{H} 11)(10.7)\end{array}$ \\
\hline 849.2 & 64.2 & 845.1 & 117.2 & $\nu(\mathrm{O} 1-\mathrm{C} 2)(38.0)+\nu(\mathrm{C} 5-\mathrm{C} 2)(15.0)+\nu(\mathrm{C} 6-\mathrm{O} 1)(10.2)$ \\
\hline 844.2 & 6.6 & 828.0 & 23.9 & $\begin{array}{l}\delta \text { ring } 2(25.8)+\nu(\mathrm{C} 6-\mathrm{O} 1)(14.9)+\delta(\mathrm{C} 5-\mathrm{H} 11) \\
\quad+\nu(\mathrm{O} 1-\mathrm{C} 2)(10.5)+\nu(\mathrm{C} 5-\mathrm{C} 2)(9.8)\end{array}$ \\
\hline 743.9 & 5.3 & 759.7 & 7.6 & $\begin{array}{l}\gamma(\mathrm{C} 3-\mathrm{H} 9)(19.6)+\nu(\mathrm{O} 1-\mathrm{C} 2)(18.9)+\gamma(\mathrm{C} 4-\mathrm{H} 10) \\
\quad+\delta \operatorname{ring} 1(11.1)\end{array}$ \\
\hline 724.4 & 16.5 & 720.2 & 16.0 & $\delta$ ring $1(35.1)+\nu(\mathrm{C} 5-\mathrm{C} 6)(10.0)$ \\
\hline \multirow[t]{5}{*}{694.8} & 11.8 & 689.1 & 12.3 & $\begin{array}{l}\gamma(\mathrm{C} 6=\mathrm{O} 7)(30.7)+\delta(\mathrm{C} 6=\mathrm{O} 7)(10.1)+\gamma(\mathrm{C} 4-\mathrm{H} 10) \\
\quad+\tau \text { ring } 1(9.8)\end{array}$ \\
\hline & & 482.7 & 8.0 & $\begin{array}{l}\delta(\mathrm{C} 6=\mathrm{O} 7)(33.7)+\tau \text { ring } 2(17.9)+\gamma(\mathrm{C} 6=\mathrm{O} 7) \\
\quad+\delta \text { ring } 1(11.7)+\nu(\mathrm{C} 5-\mathrm{C} 6)(9.7)\end{array}$ \\
\hline & & 414.0 & 3.7 & $\tau$ butterfly $(35.0)+\delta(\mathrm{C} 6=\mathrm{O} 7)(16.3)+\tau \operatorname{ring} 2(10.7)$ \\
\hline & & 315.7 & 2.4 & $\tau$ ring $2(40.2)+\tau$ butterfly $(30.5)+\nu(\mathrm{C} 5-\mathrm{C} 6)(10.0)$ \\
\hline & & 164.4 & 1.8 & $\tau$ ring $1(55.8)+\gamma(\mathrm{C} 6=\mathrm{O} 7)(25.1)+\tau$ butterfly $(11.4)$ \\
\hline
\end{tabular}

${ }^{a}$ Frequencies in $\mathrm{cm}^{-1}$, theoretical frequencies scaled by a factor of 0.978 , except for $\mathrm{CH}$ stretching modes which were multiplied by 0.968 .

${ }^{b}$ Relative integrated intensities. ${ }^{c}$ Calculated intensities in $\mathrm{km} \mathrm{mol}^{-1}$. ${ }^{d}$ PED's lower than $10 \%$ are not included. Definition of internal coordinates is given in Table S2 of the ESI. See Fig. 1 for atom numbering.

One of the possible explanations of observation of only $s$ trans isomers of the aldehyde-ketene come from the assumption that the photochemical $s$-cis $\rightarrow s$-trans isomerization is more efficient than the photoprocess in the opposite direction. Photoisomerization processes $s$-cis $\rightarrow s$-trans or $s$-trans $\rightarrow s$-cis are known from the photochemistry of dienes. ${ }^{33}$

Another reaction known from photochemistry of butadienes is the pericyclic ring closure to cyclobutene. ${ }^{34,35} \mathrm{~A}$ similar reaction-formation of cyclobutenone from conjugated ketene is reported by Moore and Decker. ${ }^{24}$ The analogous reaction starting from the $s$-cis isomers of the aldehyde-ketene would yield 4-formyl-2-cyclobutene-1-one (FCB), presented in Fig. 7.

The ground state of FCB is predicted to be higher by $c a .50$ $\mathrm{kJ} \mathrm{mol}^{-1}$ with respect to $s$-cis aldehyde-ketenes (see Fig. 8), but once FCB is photochemically created it should be stable because the barrier for the ground state opening of its ring is high (calculated value equals to $55 \mathrm{~kJ} \mathrm{~mol}^{-1}$ ). The infrared spectrum of FCB was calculated at DFT level (Table S14 and $\mathrm{S} 15$ of the ESI) $\dagger$ and the most intense of its bands was that of the $\mathrm{C}=\mathrm{O}$ stretching vibration with predicted frequency 1818 $\mathrm{cm}^{-1}$. This frequency lies between those corresponding to the $\mathrm{C}=\mathrm{O}$ stretching vibration in $\mathrm{AP}$ and $\mathrm{OOBH}$. Low intensity bands, not assigned to other species, were observed to grow at this position upon UV $(\lambda>285$ or $235 \mathrm{~nm})$ irradiation of matrices (see Fig. 4). The broad shape of these bands suggests some degree of conformational flexibility of the species responsible for these absorptions. Four-membered ring of FCB is a rigid unit, but the energy profile for internal rotation of the formyl group is quite shallow, with two non-equivalent minima (Fig. 9). Hence, the broad shape of the experimental bands at $c a .1820 \mathrm{~cm}^{-1}$ as well as their spectral position are consistent with the results of theoretical calculations carried out for FCB. Though the definitive identification of FCB as a species produced in low temperature matrices is not possible based on the analysis of a single spectral region, and other hypothetical photoproducts, e.g., benzvalene-like isomer ${ }^{5,36}$ presented in Figure $\mathrm{S} 3, \dagger$ could also give rise to bands in this spectral region, ${ }^{37}$ the proposed assignment to FCB seems to be the best explanation for the lack of observation of form $\mathrm{V}$. 


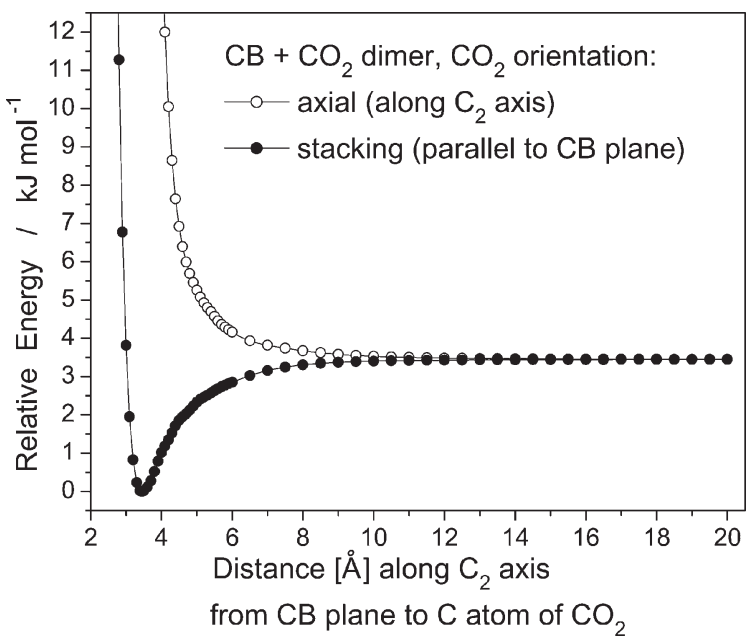

Fig. 6 Representation of the PES scan for the complex of cyclobutadiene $(\mathrm{CB})$ and $\mathrm{CO}_{2}$ in two different orientations (all the points correspond to structures with $C_{2 v}$ symmetry). Calculations were carried out at the DFT(B3LYP)/6-311++G(d,p) level of theory. Zero level corresponds to $-343.369411 E_{\mathrm{h}}$.

Table 3 Estimated energies $\left(\mathrm{kJ} \mathrm{mol}^{-1}\right)$ of the barriers separating aldehyde-ketene isomers which differ from each other by a single internal rotation. ${ }^{a}$

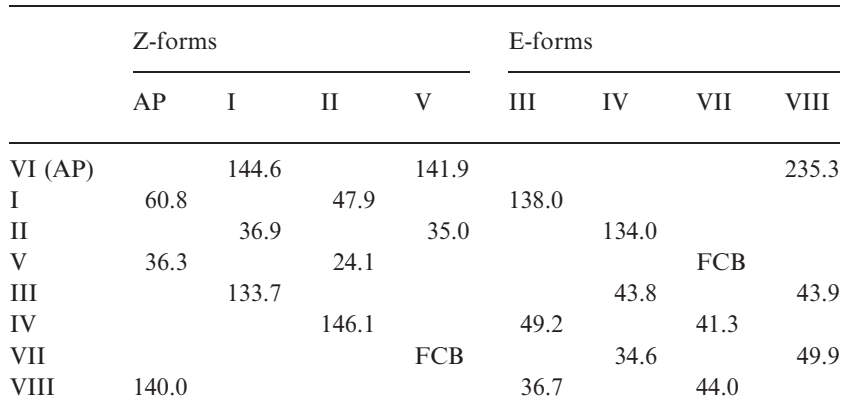

${ }^{a}$ The energies are estimated fixing the relevant reaction coordinate torsional angle at $90^{\circ}$ (all minima are planar and have all dihedral angles equal to 0 or $180^{\circ}$ ). The reactant species correspond to those indicated in the left column, while the products are indicated in the headline. The energies presented do not contain zero point vibrational energy corrections. For naming of isomers see Fig. 3. The input guess structure (marked with $X$ in Fig. 7) of a transition state for the interconversion reaction between V and VII converged to an FCB-like (form B) geometry. For the open ring ketene VI (not a minimum) the energy of AP was used as a reference. Calculation was carried out at the DFT(B3LYP) $/ 6-311++\mathrm{G}(\mathrm{d}, \mathrm{p})$ level in the electronic ground state

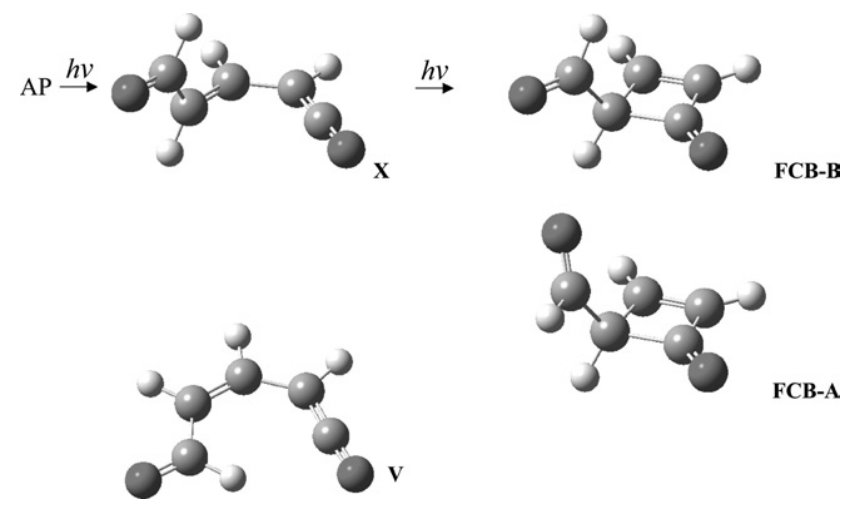

Fig. 7 Photochemical generation of excited state ketene form $\mathrm{V}$ from $\mathrm{AP}$ and subsequent photoisomerization of this species to FCB (schematic diagram). The input guess structure (marked with $\mathrm{X}$ ) of a transition state for the interconversion reaction between ketene $\mathrm{V}$ and VII converged to an FCB-like (form B) geometry.

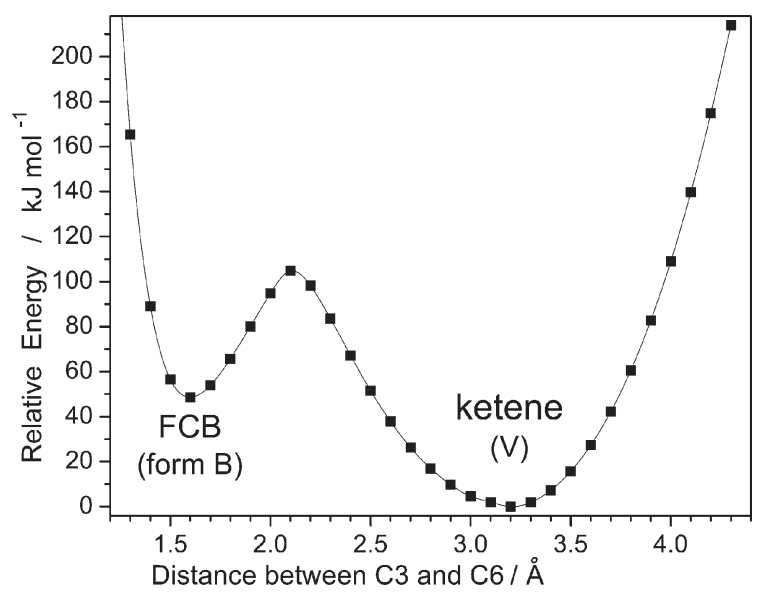

Fig. 8 Ground electronic state potential energy profile for interconversion between ketene form $\mathrm{V}$ and $\mathrm{FCB}$ (conformer B) calculated using the DFT(B3LYP)/6-311++G(d,p) method. Zero level (energy of ketene V) corresponds to $-343.426272 E_{\mathrm{h}}$.

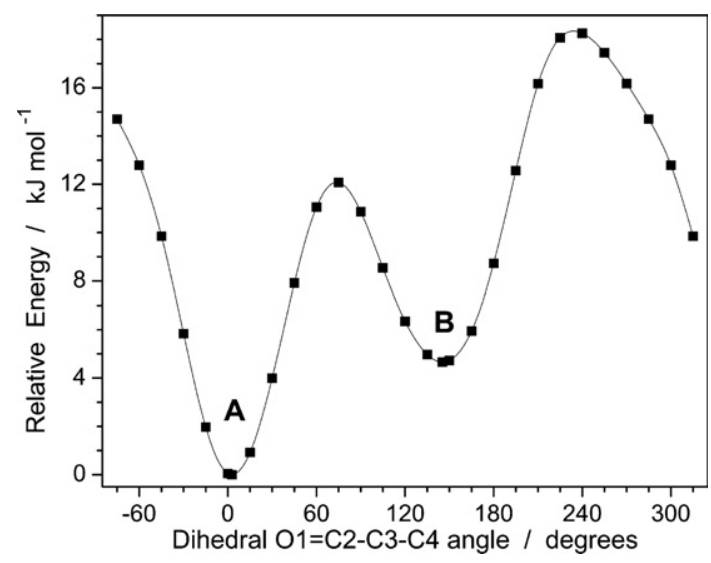

Fig. 9 Ground electronic state potential energy profile for interconversion between conformers $\mathrm{A}$ and $\mathrm{B}$ of FCB calculated using the DFT/B3LYP/6-311++G(d,p) method. Zero level (energy of form A) corresponds to $-343.409527 E_{\mathrm{h}}$.

\section{Conclusion}

In the current study of the photochemical behavior of $\alpha$-pyrone isolated in a low temperature Xe matrix, a conjugated aldehyde-ketene was observed as the product of the dominating Norrish type I, ring opening reaction. $\mathrm{Z}$ isomers of the aldehyde-ketene appeared as direct products of UV-induced $\alpha$-bond cleavage reaction, whereas $\mathrm{E}$ isomers were subsequently generated by photochemical cis-trans isomerization around the central $\mathrm{C}=\mathrm{C}$ double bond. Ring closure reverse reaction, induced by longer wavelength UV radiation, occurred only for $\mathrm{Z}$ isomers, while $\mathrm{E}$ forms were unaffected by $\lambda>337 \mathrm{~nm}$ irradiation. The formation of 4-formyl-2-cyclobutene-1-one, by photochemical ring closure of aldehydeketene isomers with the central $\mathrm{C}=\mathrm{C}$ bond and the ketene group in $s-c i s$ position with respect to each other, was also proposed to occur, being in consonance with the lack of any bands ascribable to those aldehyde-ketene isomers in the IR spectra of the UV irradiated matrices.

Photoproduction of the Dewar valence isomer of $\alpha$-pyrone is also accounted for. This species appeared concomitantly with the conjugated ketenes upon $\lambda>285 \mathrm{~nm}$ irradiation. Upon $\lambda>235 \mathrm{~nm}$ irradiation it decomposed to give rise to a cyclobutadiene complex with carbon dioxide. Comparison of experimental observations with theoretical predictions confirmed the stacking geometry of the cyclobutadiene- $-\mathrm{CO}_{2}$ complex. 
Identical photochemical behavior was also found for the compound in both argon (Fig. S4) $\dagger$ and krypton matrices, indicating that the observed processes do not depend on the inert gas used.

\section{Acknowledgements}

IR, SB and RF acknowledge the financial support from Fundação para a Ciência e a Tecnologia, Lisbon (grant FCT \#SFRH/BPD/1661/2000 and research project POCTI/ 43366/QUI/2001, also supported by FEDER). SB also acknowledges support from the Centre of Excellence ASPECT financed by the European Commission within the contract number G6MA-CT-2002-04021.

\section{References}

1 R. S. Becker, S. Chakravorti, C. Gartner and M. G. Miguel, J.Chem. Soc., Faraday Trans., 1993, 89, 1007.

2 A. Lopes, J. Seixas de Melo, A. J. Martins, A. L. Maçanita, F. S. Pina, H. Wamhoff and E. C. Mello, Environ. Sci. Technol., 1995, 29, 562 .

3 S. Seixas de Melo, G. Quinteiro, J. Pina, S. Breda and R. Fausto, J. Mol. Struct., 2001, 565-566, 59.

4 P. De Mayo, Adv. Org. Chem., 1960, 2, 394.

5 W. H. Pirkle and L. H. McKendry, J. Am. Chem. Soc., 1969, 91, 1179.

6 E. J. Corey and J. Streith, J. Am. Chem. Soc., 1964, 86, 950.

7 D. J. Cram, M. E. Tanner and R. Thomas, Angew. Chem., Int. Ed. Engl., 1991, 30, 1024.

8 B. R. Arnold, C. E. Brown and J. Lusztyk, J. Am. Chem. Soc., 1993, 115, 1576

9 R. G. S. Pong, B. S. Huang, J. Laureni and A. Krantz, J. Am. Chem. Soc., 1977, 99, 4153.

10 R. G. S. Pong and J. S. Shirk, J. Am. Chem. Soc., 1973, 95, 248.

11 O. L. Chapman, C. L. McIntosh and J. Pacansky, J. Am. Chem. Soc., 1973, 95, 244

12 O. L. Chapman, C. L. McIntosh and J. Pacansky, J. Am. Chem. Soc., 1973, 95, 614 .

13 R. L. Redington, J. Chem. Phys., 1998, 109, 10781.

14 G. Maier, H.-G. Hartan and T. Sayrac, Angew. Chem., Int. Ed. Engl., 1976, 15, 226.

15 S. Breda, L. Lapinski, I. Reva and R. Fausto, J. Photochem. Photobiol., A, 2003, in press, Manuscript No. JPC6410.

16 A. D. Becke, Phys. Rev. A, 1988, 38, 3098.

17 C. T. Lee, W. T. Yang and R. G. Parr, Phys. Rev. B, 1988, 37,785 .
18 S. H. Vosko, L. Wilk and M. Nusair, Can. J. Phys., 1980, 58, 1200

19 J. H. Schachtschneider, Technical Report, Shell Development Co., Emeryville, CA, 1969.

20 M. J. Frisch, G. W. Trucks, H. B. Schlegel, G. E. Scuseria, M. A. Robb, J. R. Cheeseman, V. G. Zakrzewski, J. A. Montgomery, Jr., R. E. Stratmann, J. C. Burant, S. Dapprich, J. M. Millam, A. D. Daniels, K. N. Kudin, M. C. Strain, O. Farkas, J. Tomasi, V. Barone, M. Cossi, R. Cammi, B. Mennucci, C. Pomelli, C. Adamo, S. Clifford, J. Ochterski, G. A. Petersson, P. Y. Ayala, Q. Cui, K. Morokuma, D. K. Malick, A. D. Rabuck, K. Raghavachari, J. B. Foresman, J. Cioslowski, J. V. Ortiz, B. B. Stefanov, G. Liu, A. Liashenko, P. Piskorz, I. Komaromi, R. Gomperts, R. L. Martin, D. J. Fox, T. Keith, M. A. Al-Laham, C. Y. Peng, A. Nanayakkara, C. Gonzalez, M. Challacombe, P. M. W. Gill, B. G. Johnson, W. Chen, M. W. Wong, J. L. Andres, M. Head-Gordon, E. S. Replogle and J. A. Pople, GAUSSIAN 98 (Revision A.9), Gaussian, Inc., Pittsburgh, PA, 1998.

21 R. Fausto, G. Quinteiro and S. Breda, J. Mol. Struct., 2001, 598, 287.

22 B. S. Huang, R. G. S. Pong, J. Laureni and A. Krantz, J. Am. Chem. Soc., 1977, 99, 4154.

23 J. P. Guthrie, C. L. McIntosh and P. De Mayo, Can. J. Chem., 1970, 48, 237.

24 H. W. Moore and O. H. W. Decker, Chem. Rev., 1986, 86, 821.

25 R. Fausto, A. Kulbida and O. Schrems, J. Chem. Soc., Faraday Trans., 1995, 91, 3755.

26 E. M. S. Maçôas, R. Fausto, J. Lundell, M. Pettersson, L. Khriachtchev and M. Räsänen, J. Phys. Chem. A, 2001, 105, 3922

27 L. Lapinski, M. J. Nowak, A. Les and L. Adamowicz, J. Am. Chem. Soc., 1994, 116, 1461.

28 N. J. Turro, Modern Molecular Photochemistry, University Science Books, Sausalito, California, 1991.

29 M. Klessinger, J. Michl, Excited States and Photochemistry of Organic Molecules, VCH, New York, 1995.

30 R. S. Becker, Theory and Interpretation of Fluorescence and Phosphorescence, Wiley Interscience, New York, 1969.

31 F. Neumann and K. Jug, J. Org. Chem., 1994, 59, 6437.

32 M. Dulce Faria, J. J. C. Teixeira-Dias and R. Fausto, Vib. Spectrosc., 1991, 2, 107.

33 B. R. Arnold, V. Balaji, J. W. Downing, J. G. Radziszewski, J. J. Fisher and J. Michl, J. Am. Chem. Soc., 1991, 113, 2910.

34 M. Olivucci, F. Bernardi, S. Ottani and M. A. Robb, J. Am. Chem. Soc., 1994, 116, 2034.

35 M. Olivucci, I. N. Ragazos, F. Bernardi and M. A. Robb, J. Am. Chem. Soc., 1993, 115, 3710.

36 E. J. Corey and W. H. Pirkle, Tetrahedron Lett., 1967, 8, 5255; E. J. Corey and W. H. Pirkle, Tetrahedron Lett., 1968, 9, 255 (Erratum).

37 All hypothetical species have the strongest predicted absorption in the carbonyl stretching region. Predicted absorption bands due to other vibrations have much lower intensity and are not discernible under the present experimental conditions. 